\title{
Effect of Cooling Rate on the Formation of Nonmetallic Inclusions in X80 Pipeline Steel
}

\author{
Xianguang Zhang, Wen Yang, Haikun Xu and Lifeng Zhang * \\ School of Metallurgical and Ecological Engineering, University of Science and Technology Beijing, \\ Beijing 100083, China; xgzhang@ustb.edu.cn (X.Z.); wenyang@ustb.edu.cn (W.Y.); sdm_xhk@163.com (H.X.) \\ * Correspondence: zhanglifeng@ustb.edu.cn; Tel.: +86-10-62332267
}

Received: 5 March 2019; Accepted: 25 March 2019; Published: 29 March 2019

\begin{abstract}
Nonmetallic inclusions have a strong influence on the hydrogen-induced cracking (HIC) and sulfide stress cracking (SSC) in pipeline steels, which should be well controlled to improve the steel resistance to HIC and SSC. The effects of cooling rate on the formation of nonmetallic inclusions have been studied both experimentally and thermodynamically. It was found that the increasing cooling rate increased the number density and decreased the size of the inclusions, while the inverse results were obtained by decreasing the cooling rate. Furthermore, as the cooling rate decreased from 10 to $0.035 \mathrm{~K} / \mathrm{s}$, the inclusions were changed from $\mathrm{Al}_{2} \mathrm{O}_{3}-\mathrm{CaO}$ to $\mathrm{Al}_{2} \mathrm{O}_{3}-\mathrm{CaO}-\mathrm{MgO}-\mathrm{CaS}$. At a high cooling rate, the reaction time is short and the inclusions cannot be completely transformed which should be mainly formed at high temperatures. While, at low cooling rate, the inclusions can be gradually transformed and tend to follow the equilibrium compositions.
\end{abstract}

Keywords: pipeline steel; inclusions; cooling rate; composition

\section{Introduction}

High-grade pipeline steels have been widely used in the construction of long-distance oil and gas transportation systems, which requires good combination of high strength, toughness, corrosion resistance and weldability. Hydrogen-induced cracking (HIC) and sulfide stress cracking (SSC) have been recognized as the vital threats to the safety of the pipeline operation, and caused significant economic losses throughout the world [1-8]. It has been acknowledged [5,9] that nonmetallic inclusions are one of the dominant factors affecting the HIC and SSC in pipeline steels, especially the large inclusions with string shape. Therefore, it is crucial to control the inclusions in pipeline steels to improve the steel resistance to HIC and SSC.

There are several kinds of inclusions in pipeline steel due to its complex alloy elements. The inclusions are mainly identified as aluminum oxides, calcium oxides or calcium sulfide, magnesium oxides and manganese compounds [10]. It was reported that the calcium aluminate with low melting temperature can be elongated into string shape after rolling, which is harmful to the performance of pipeline steels [11-13]. Researchers proposed that the inclusions should be controlled to $\mathrm{CaO}-\mathrm{Al}_{2} \mathrm{O}_{3}-\mathrm{CaS}, \mathrm{CaO}-\mathrm{CaS}$ type $[11]$ or $\mathrm{Al}_{2} \mathrm{O}_{3}-\mathrm{CaS}$ type $[14,15]$ to reduce their detrimental effects. Hence, the type and composition of the inclusions are important to pipeline steels which should be well controlled. Inclusions are usually controlled by adjusting compositions of slag or/and steel during steelmaking process [16-21]. In addition, the nonmetallic inclusions can transform even during and after solidification. It was reported that in stainless steel the inclusion of $\mathrm{MnO}_{-} \mathrm{SiO}_{2}$ can transform to $\mathrm{MnO}-\mathrm{Cr}_{2} \mathrm{O}_{3}$ spinel during heat treatment and the transformation rate depended on both temperature and size of the inclusions [22]. Therefore, the evolution of the inclusions during the cooling process is also very important for the formation of inclusions in the final product. 
Cooling rate is an important parameter during the continuous casting, which largely changes the temperature and time of the steels experienced during the solidification and subsequent solid-state cooling process. Hence, the cooling rate may have a strong influence on the precipitation and transformation behaviors of the inclusions in pipeline steels. However, the previous works were mainly focused on the influences of compositions of the slag or steels on the formation of the inclusions. Little attention has been paid to the evolution of inclusions at different cooling rates. Goto et al. [23,24] investigated the effects of cooling rate during solidification on the formation of oxides in plain low carbon steels. It was found that $[23,24]$ the amount, size and compositions of the oxides are strongly influenced by the cooling rate. However, according to the best of the authors' knowledge, no systematic work has been reported regarding the effects of cooling rate on the formation of inclusions in high-grade pipeline steels, especially the type and composition of the inclusions, which requires a stricter control in inclusions. In the current work, the number, size distributions and compositions of inclusions in X80 pipeline steel formed at different cooling rates were studied systematically to clarify the effects of cooling rate on the precipitation, growth and transformation of the inclusions in pipeline steel.

\section{Materials and Methods}

X80 pipeline steel was used in this study, the composition of which is shown in Table 1. The production procedure of $\mathrm{X} 80$ pipeline steel is "basic oxygen furnace (BOF) $\rightarrow$ ladle furnace (LF) refining $\rightarrow \mathrm{RH}$ refining $\rightarrow \mathrm{Ca}$ treatment $\rightarrow$ soft-blowing $\rightarrow$ continuous casting". Molten steel specimens were taken from the ladle furnace after the Ca treatment and soft-blowing for $600 \mathrm{~s}$, and quenched into water immediately. Figure 1a shows a schematic of the thermal history for re-melting and cooling treatments of the specimens used in this study. The specimens were first re-melted at $1873 \mathrm{~K}$ for $600 \mathrm{~s}$ in a Si-Mo resistance furnace under an argon atmosphere in $\mathrm{MgO}$ crucibles, as schematically shown in Figure 1b. After that, the crucibles were taken out and cooled at three different cooling rates by employing water, air or furnace, respectively, as schematically shown in Figure 1a.

The cooling rate in air was evaluated from Equation (1) [25] which relates the secondary dendrite arm spacing with the cooling rate and it is valid for a carbon content below 0.53 mass $\%$.

$$
\lambda=148 C_{R}^{-0.38,}
$$

where, $\lambda$ represents the secondary dendrite arm spacing $(\mu \mathrm{m})$, and $C_{R}$ is the cooling rate $(\mathrm{K} / \mathrm{s})$. The average secondary dendrite arm spacing was measured to be around $191 \mu \mathrm{m}$, and thus the average cooling rate in air was estimated to be $0.51 \mathrm{~K} / \mathrm{s}$. The dendritic structure for the samples cooled in furnace and in water did hardly produce clear images. The cooling rates in furnace and in water were estimated to be $0.035 \mathrm{~K} / \mathrm{s}$ [26] using a pyrometer and $10 \mathrm{~K} / \mathrm{s}$ using thermocouples [27], respectively, from the temperature of 1873 to $983 \mathrm{~K}$.

After cooling to room temperature, the samples were cut and polished for analyzing the distribution of the inclusions. The morphology, number, area and chemical composition of inclusions in the samples were detected by using an automated Scanning Electron Microscope-Energy Dispersive Spectrometer (SEM-EDS, FEI, Pittsburgh, PA, USA) inclusion analysis system (Aspex Explorer) operated at $15 \mathrm{kV}$. The minimum detectable inclusion was set as approximately $0.5 \mu \mathrm{m}$, and the maximum diameter was chosen as the size of inclusion. The area of around $17 \mathrm{~mm}^{2}$ were scanned for the of inclusions analyses for each sample.

Table 1. Chemical composition of the alloy used in this study (mass\%).

\begin{tabular}{ccccccccc}
\hline $\mathbf{C}$ & $\mathbf{S i}$ & $\mathbf{M n}$ & $\mathbf{P}$ & $\mathbf{S}$ & $\mathbf{A l}$ & $\mathbf{T i}$ & $\mathbf{C a}$ & $\mathbf{O}$ \\
\hline 0.06 & 0.20 & 1.72 & 0.014 & 0.0015 & 0.03 & 0.015 & 0.0016 & 0.0012 \\
\hline
\end{tabular}


(a)

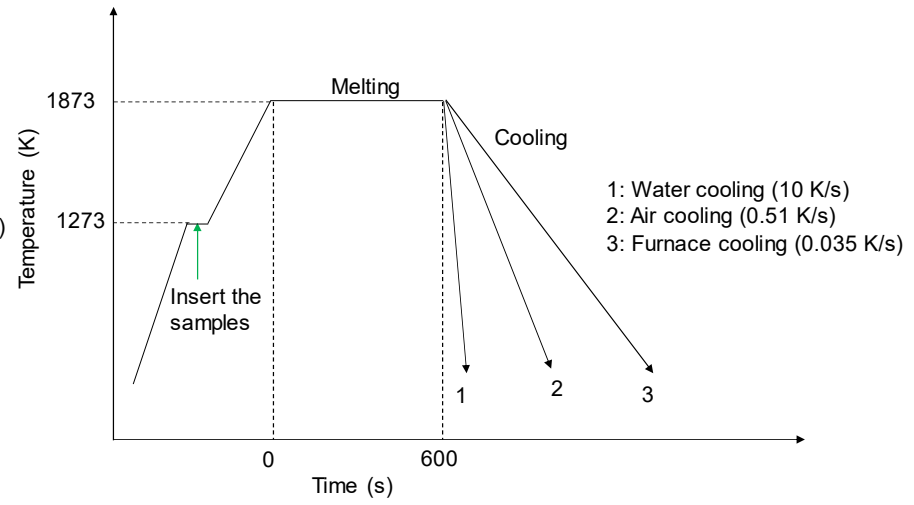

(b)

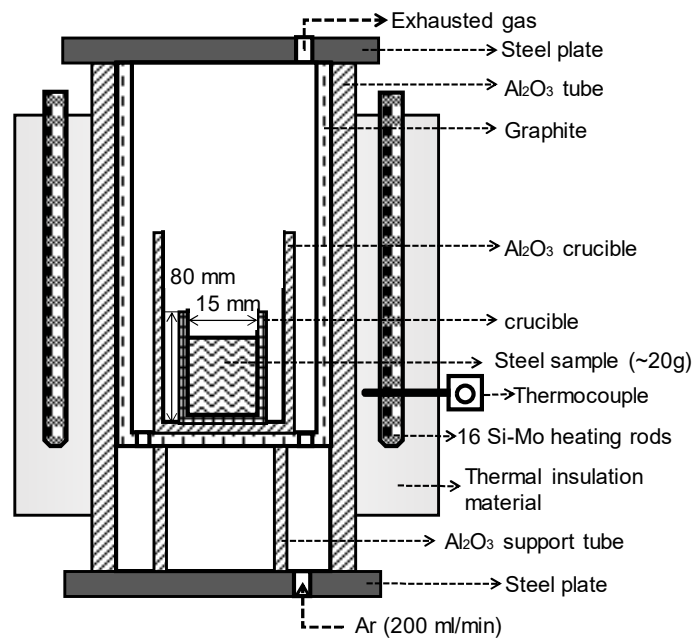

Figure 1. Schematic illustrations of (a) the thermal history for re-melting and cooling treatments of the specimens and (b) the Si-Mo resistance furnace employed in this study.

Two statistical parameters, area fraction and number density, are defined as the following two equations to characterize nonmetallic inclusions.

$$
A F=\frac{A_{\text {inclusion }}}{A_{\text {total }}}
$$

where, $A F$ is the area fraction of inclusions, ppm; $A_{\text {inclusion }}$ is the total area of the detected inclusions, $\mu \mathrm{m}^{2}$; and $A_{\text {total }}$ is the area scanned, $\mathrm{mm}^{2}$.

$$
N D=\frac{n}{A_{\text {total }}}
$$

where, $N D$ is the number density of inclusions, per $\mathrm{mm}^{2}$; and $n$ is number of detected inclusions on the area of $A_{\text {total }}$.

\section{Results and Discussion}

\subsection{Characterization of the Inclusions Formed at Different Cooling Rates}

The element mapping of a typical inclusion formed at the cooling rate of $10 \mathrm{~K} / \mathrm{s}$ (water cooling) is shown in Figure 2a. The morphology of the inclusion is spherical and it mainly contains the elements of $\mathrm{Al}, \mathrm{Ca}, \mathrm{O}$, and a small amount of $\mathrm{Mg}$. The composition and size distributions of inclusions were plotted in ternary phase diagrams, as shown in Figure $2 b-c$, where the scanning area and number of inclusions are presented and the black star indicates the average composition. Most of the inclusions are the $\mathrm{Al}_{2} \mathrm{O}_{3}-\mathrm{CaO}$, with a very small amount of $\mathrm{MgO}$ and $\mathrm{CaS}$. The diameters of the inclusions are 
mostly smaller than $3.5 \mu \mathrm{m}$. Figure $2 \mathrm{~d}$ shows the variation in composition of the inclusions against its equivalent diameter. The contents of $\mathrm{Al}_{2} \mathrm{O}_{3}$ and $\mathrm{CaO}$ are almost stable regardless the size of the inclusions, and the contents of $\mathrm{MgO}$ and $\mathrm{CaS}$ are very low.

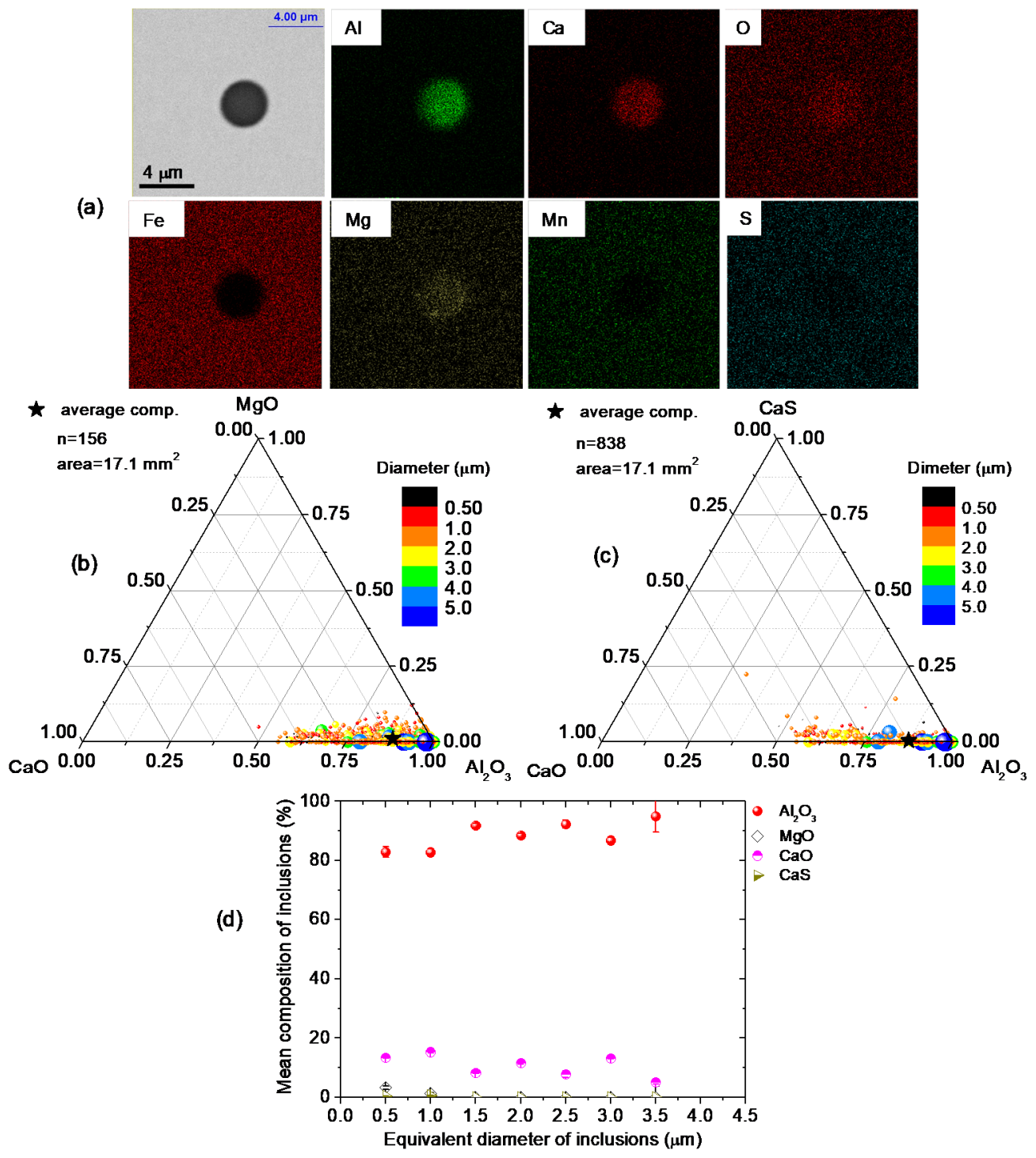

Figure 2. (a) Element mapping of a typical inclusions formed at the cooling rate of $10 \mathrm{~K} / \mathrm{s}$. Summary of the $(\mathbf{b}-\mathbf{c})$ composition and size distributions of inclusions and (d) variations in composition of inclusions against its diameter formed at the cooling rate of $10 \mathrm{~K} / \mathrm{s}$.

The element mapping of a typical inclusion formed at the cooling rate of $0.51 \mathrm{~K} / \mathrm{s}$ (air cooling) is shown in Figure 3a. The morphology of the inclusion is spherical and it mainly contains the elements of $\mathrm{Al}, \mathrm{Ca}, \mathrm{O}$. The content of Mg seems slightly higher than that of the water-cooled specimen shown in Figure 2a. The composition and size distributions of inclusions are shown in Figure 3b-c. Most of the inclusions are the $\mathrm{Al}_{2} \mathrm{O}_{3}-\mathrm{MgO}-\mathrm{CaO}$ and $\mathrm{Al}_{2} \mathrm{O}_{3}-\mathrm{CaO}-\mathrm{CaS}$. In addition, the diameters of the inclusions are mostly smaller than $3 \mu \mathrm{m}$. The average composition of the inclusions is about $62 \% \mathrm{Al}_{2} \mathrm{O}_{3}-3 \%$ $\mathrm{MgO}-26 \% \mathrm{CaO}-9 \% \mathrm{CaS}$. Figure $3 \mathrm{~d}$ shows the variation in composition of the inclusions as a function of its diameter. With the increase in diameter of inclusions, the $\mathrm{Al}_{2} \mathrm{O}_{3}$ and $\mathrm{CaO}$ contents are increased, while the CaS content is decreased. Around 10\% CaS was contained in inclusions with the diameter of $0.5 \mu \mathrm{m}$. 


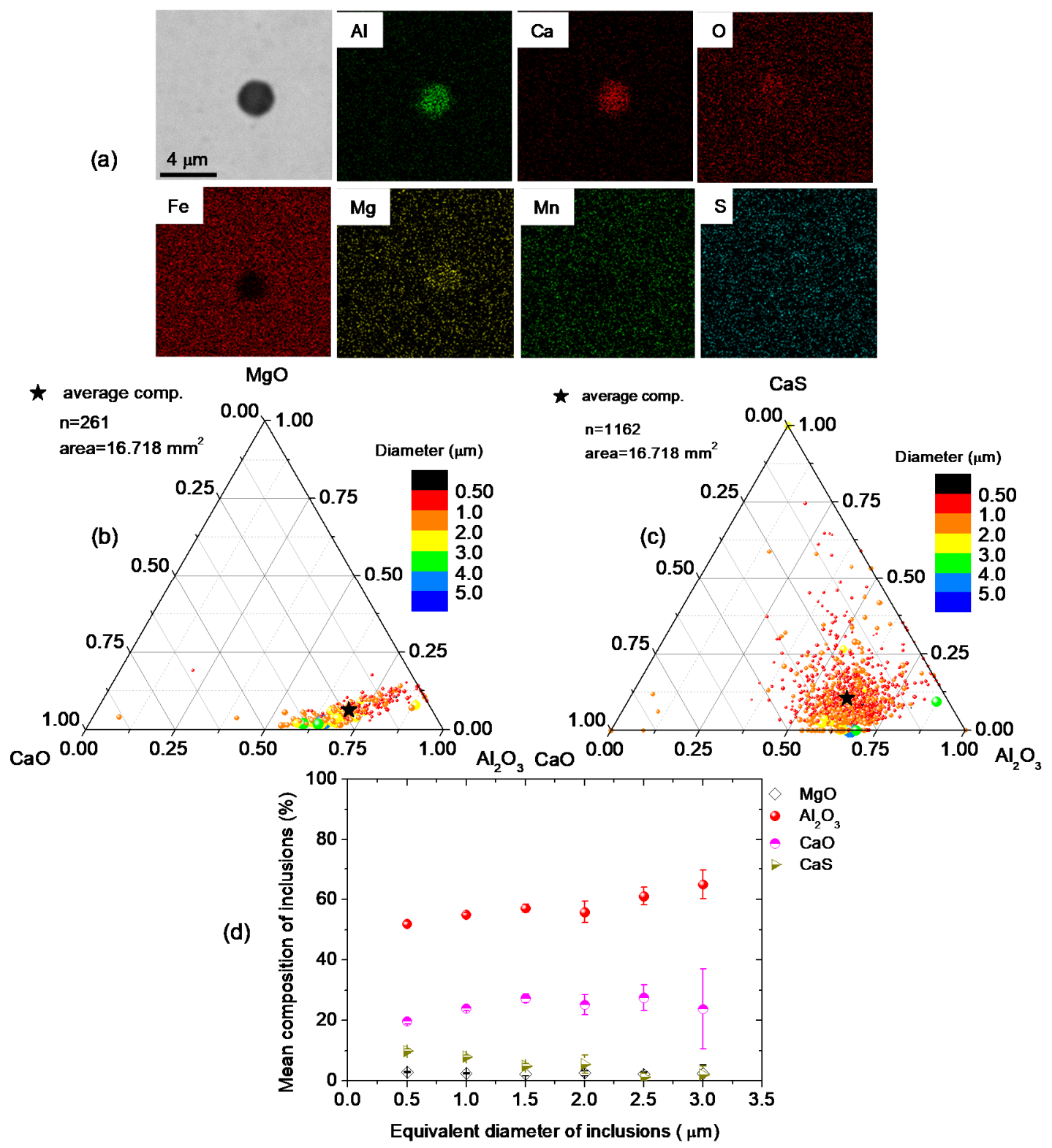

Figure 3. (a) Element mapping of a typical inclusions formed at the cooling rate of $0.51 \mathrm{~K} / \mathrm{s}$. Summary of the $(\mathbf{b}-\mathbf{c})$ composition and size distributions of inclusions and (d) variations in composition of inclusions against its diameter formed at the cooling rate of $0.51 \mathrm{~K} / \mathrm{s}$.

The element mapping of a typical inclusion at the cooling rate of $0.035 \mathrm{~K} / \mathrm{s}$ (furnace cooling) is shown in Figure 4a. The morphology of the inclusion is spherical and it mainly contains the elements of $\mathrm{Al}, \mathrm{Ca}, \mathrm{O}, \mathrm{Mg}$ and $\mathrm{S}$. The contents of $\mathrm{Mg}$ and $\mathrm{S}$ are much higher than that of the high cooling rates as shown in Figures 2a and 3a. More importantly, it can be noticed that the inclusion is not as uniform as that of the inclusions formed at a high cooling rates (Figures 2a and 3a). According to the element distribution, the out-layer of the inclusion is $\mathrm{CaS}$, while the core is composed by $\mathrm{Al}_{2} \mathrm{O}_{3}-\mathrm{MgO}-\mathrm{CaO}$. The composition and size distributions of the inclusions formed at the cooling rate of $0.035 \mathrm{~K} / \mathrm{s}$ (furnace cooling) are shown in Figure $4 \mathrm{~b}$,c. Most of the inclusions were the $\mathrm{Al}_{2} \mathrm{O}_{3}-\mathrm{MgO}-\mathrm{CaO}$ and $\mathrm{Al}_{2} \mathrm{O}_{3}-\mathrm{CaO}-\mathrm{CaS}$. The diameters of inclusions are mostly larger than $3 \mu \mathrm{m}$ and the number of inclusions is low. The average composition of inclusions is about $76 \% \mathrm{Al}_{2} \mathrm{O}_{3}-7 \% \mathrm{MgO}-3 \% \mathrm{CaO}-14 \% \mathrm{CaS}$. 
(a)
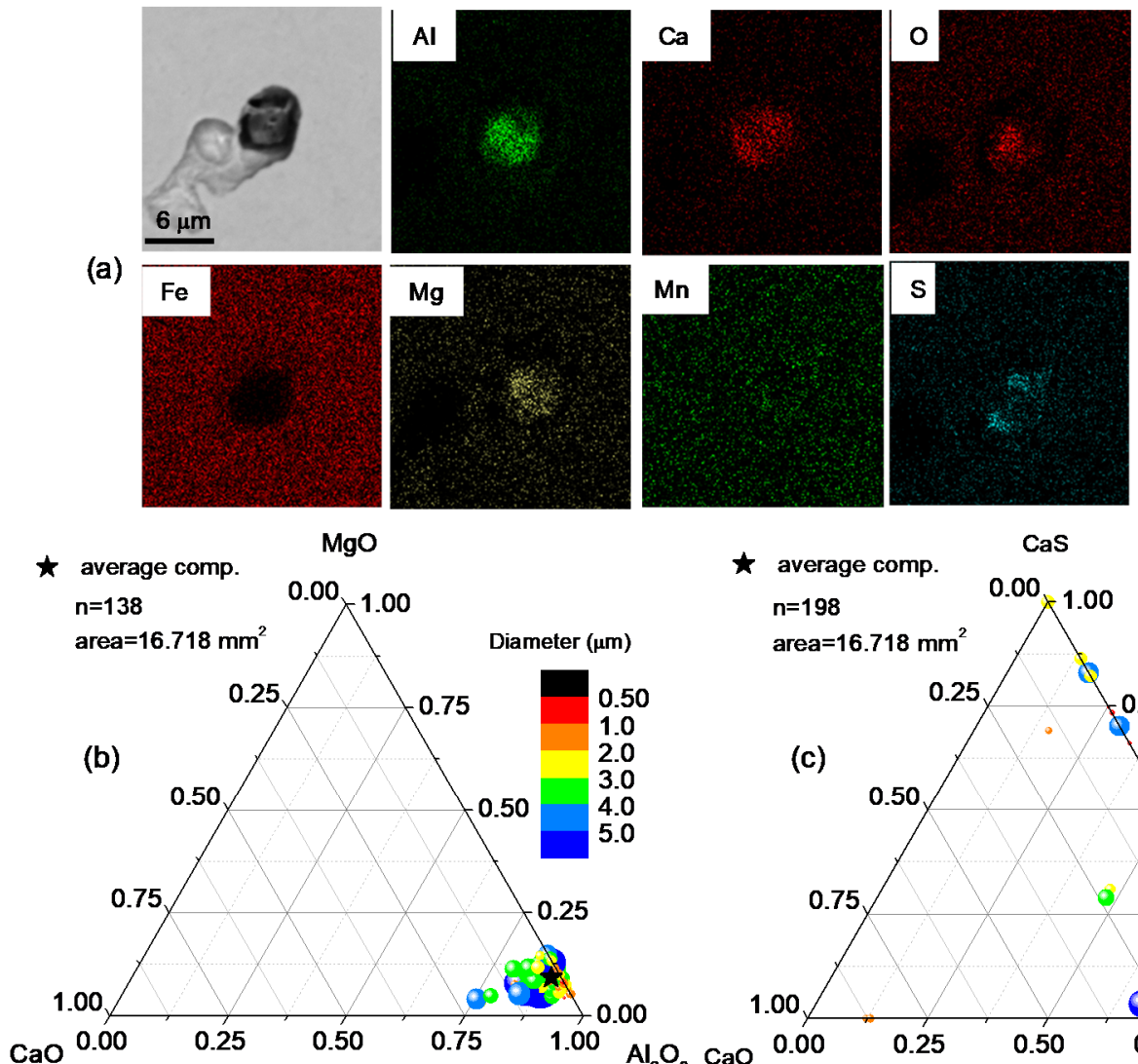

area $=16.718 \mathrm{~mm}^{2}$

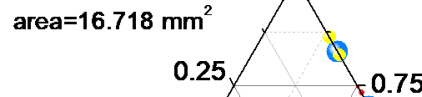

Diameter $(\mu \mathrm{m})$

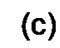

(c)

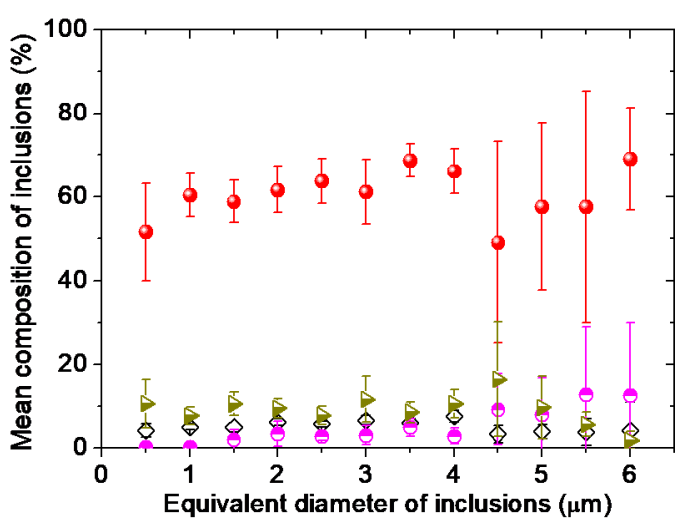

$\diamond \mathrm{MgO}$

- $\mathrm{Al}_{2} \mathrm{O}_{3}$

- $\mathrm{CaO}$

$\rightarrow$ Cas

Figure 4. (a) Element mapping of a typical inclusions formed at the cooling rate of $0.035 \mathrm{~K} / \mathrm{s}$. Summary of the $(\mathbf{b}-\mathbf{c})$ composition and size distributions of inclusions and (d) variations in composition of inclusions against its diameter formed at the cooling rate of $0.035 \mathrm{~K} / \mathrm{s}$.

Figure $4 \mathrm{~d}$ shows the variation in composition of inclusions against its diameter. The content of $\mathrm{Al}_{2} \mathrm{O}_{3}$ increases with the increase in diameter of the inclusions up to $4 \mu \mathrm{m}$, then it has a large fluctuation with the further increase in diameter. The content of $\mathrm{CaO}$ is slightly increased in the inclusions larger than $4 \mu \mathrm{m}$. The contents of $\mathrm{CaS}$ and $\mathrm{MgO}$ do not show strong dependence on the size of the inclusions.

Table 2 summarized the mean composition of the inclusions that were formed at different cooling rates. At a cooling rate of $10 \mathrm{~K} / \mathrm{s}$, the inclusions are mostly $\mathrm{Al}_{2} \mathrm{O}_{3}-\mathrm{CaO}$ with a very small amount of $\mathrm{CaS}$ and $\mathrm{MgO}$. When the cooling rate is decreased to $0.51 \mathrm{~K} / \mathrm{s}$, the contents of $\mathrm{CaO}, \mathrm{CaS}$ and $\mathrm{MgO}$ are increased. As the cooling rate is further decreased to $0.035 \mathrm{~K} / \mathrm{s}$, the contents of $\mathrm{CaS}$ and $\mathrm{MgO}$ are further increased, while the $\mathrm{CaO}$ content is decreased due to the transition of the $\mathrm{CaO}$ to $\mathrm{CaS}$. 
Table 2. Average composition of the inclusions formed at various cooling rates in X80 pipeline steel (mass\%).

\begin{tabular}{ccccc}
\hline Cooling Rate, $\mathbf{K} / \mathbf{s}$ & $\mathrm{Al}_{\mathbf{2}} \mathbf{O}_{\mathbf{3}}$ & $\mathbf{C a O}$ & $\mathbf{C a S}$ & $\mathbf{M g O}$ \\
\hline 10 & 86.23 & 12.38 & 0.34 & 1.05 \\
0.51 & 61.72 & 26.3 & 9.16 & 2.82 \\
0.035 & 75.91 & 3.02 & 14.24 & 6.83 \\
\hline
\end{tabular}

\subsection{Effects of Cooling Rate on the Formation of the Inclusions}

Figure $5 \mathrm{a}, \mathrm{b}$ shows the variation in number density and area fraction of inclusions as a function of its diameters formed at different cooling rates, respectively. The peak position of the number density appears at the diameter of around $1 \mu \mathrm{m}$ for the cases of various cooling rates, then it gradually decreases with the increase in diameter of the inclusions. The low cooling rate of $0.035 \mathrm{~K} / \mathrm{s}$ results in relatively uniform distributions in size and area fractions of the inclusions. The high cooling rates of 10 and $0.51 \mathrm{~K} / \mathrm{s}$ are similar in number density and area fraction distributions. The total number density of the inclusions formed at various cooling rates is summarized in Figure $5 \mathrm{c}$. The number density increases dramatically with the increase in cooling rate from 0.035 to $0.51 \mathrm{~K} / \mathrm{s}$, then it becomes almost constantwith the further increase in heating rate. The area fraction and average diameter of the inclusions formed at different cooling rates are shown in Figure 5d,e, respectively. With the increase in cooling rate from 0.035 to $0.51 \mathrm{~K} / \mathrm{s}$, the area fraction and average diameter are decreased, and then theybecome almost constant.

The number density of the inclusions should be related with the nucleation of the inclusions. According to the classical homogenous nucleation theory, as for a homogeneous nucleation of an inclusion in liquid steel, the activation energy for nucleation can be written as [28]

$$
\Delta G^{*}=\frac{16 \pi \sigma^{3}}{3 \Delta G_{v}^{2}}=\frac{16 \pi}{3} \sigma^{3} \frac{V_{m}^{2}}{(R T \ln \eta)^{2}}
$$

where $\sigma$ is the interfacial tension between the inclusion and liquid steel, $\Delta G_{v}$ the driving force for the inclusion nucleation, $V_{m}$ the molar volume of the inclusion and $\eta$ is the supersaturation, viz., the ratio of activities of precipitating elements to the solubility product.

The critical radius, $\mathrm{r}^{*}$, for nucleation is given by

$$
\mathrm{r}^{*}=-2 \sigma / \Delta G_{v}
$$

The nucleation rate is written as [28]

$$
I=K_{Z} \Gamma_{A} N_{A} \exp \left(\frac{-\Delta G^{*}}{k T}\right) \exp (-\tau / t),
$$

where $K_{Z}$ is the Zeldovitch factor, the value for $K_{Z}$ is about $10^{-2} . \Gamma_{A}$ is the jump frequency of atom A on the nucleus surface and is proportional to its diffusion coefficient in the liquid phase. $N_{A}$ is the atomic concentration of atom A per unit volume. $k$ is the Boltzmann's constant and $T$ is the absolute temperature. $\tau$ is the incubation time, when the time $t$ is larger than $\tau$, the nucleation rate is stationary. Indeed, the pre-exponent factor is usually assumed to be constant and in the range of $10^{35}-10^{45}\left(\mathrm{~m}^{-3} \cdot \mathrm{s}^{-1}\right)$. Therefore, according to Equation (6), the nucleation rate is inversely proportional to the activation energy $\Delta G^{*}$. 

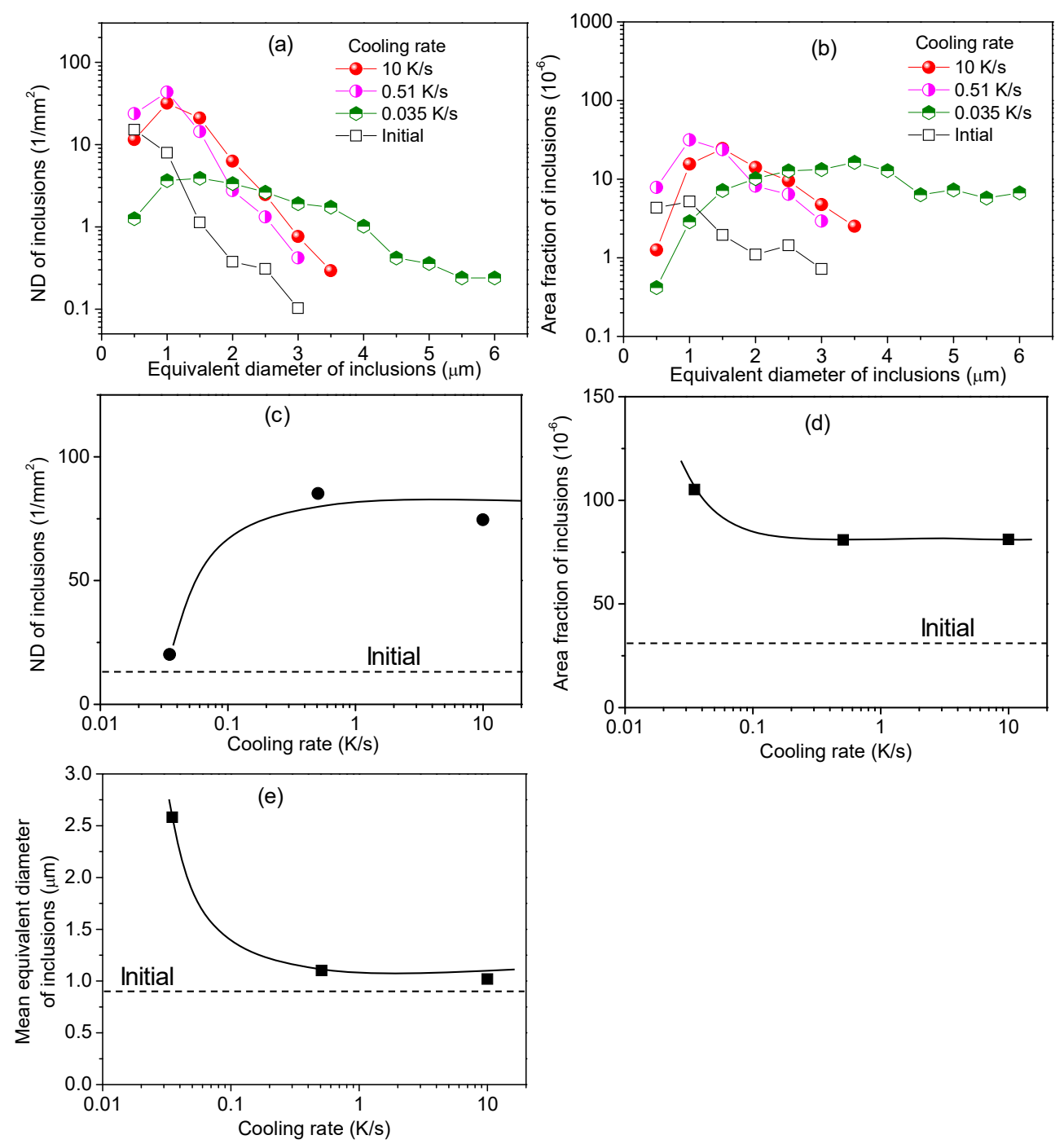

Figure 5. Variation in (a) number density and (b) area fraction of inclusions against its diameter under different cooling rates. The effects of cooling rate on the (c) number density, (d) area fraction and (e) mean equivalent diameter of the inclusions.

At a high cooling rate, the supersaturation (driving force) for inclusion nucleation is larger, due to the increase in elements segregation [24], which decreased the activation energy $\left(\Delta G^{*}\right)$ and the critical radius ( $\mathrm{r}^{*}$ ) for nucleation, according to Equations (4) and (5). This indicates that the nucleation become easier at a high driving force. On the other hand, the increase in driving force promotes the nucleation rate according to Equation (6). This should result in the high number density of the inclusions at a high cooling rate. It needs to point out that the supersaturation may be not always increase with the increase in cooling rate, and it may have an upper limit above which the supersaturation may not change obviously. This can be the reason for the almost constant number density of inclusions above $0.51 \mathrm{~K} / \mathrm{s}$.Furthermore, because the driving force for nucleation is changing in the present work, which is difficult to be evaluated, qualitative analysis is carried out in this study.

The low cooling rate has a low driving force for nucleation results in low number density of inclusions. On the other hand, at a low cooling rate, the inclusions have longer time to grow, the Ostwald-ripening effect is pronounced which results in coarse and low number density of inclusions.

In order to understand the effects of cooling rate on the composition of the inclusions, the contents of the various inclusions against the temperature in the pipeline steel was calculated by Fact Sage, which is shown in Figure 6a. The steel was melted at $1873 \mathrm{~K}$ as indicated in by a broken line in the phase 
diagram, at which all the inclusions were in liquid phase. With the decrease in temperature, the amount of liquid inclusions including $\mathrm{CaO}(\mathrm{l})$ and $\mathrm{Al}_{2} \mathrm{O}_{3}(\mathrm{l})$ is increased at first and then it is decreased. During the solidification, the liquid inclusions gradually disappeared, and the solid inclusions including CaS, $\mathrm{MgO}-\mathrm{Al}_{2} \mathrm{O}_{3}$ spinels and $\mathrm{CaO}-2 \mathrm{Al}_{2} \mathrm{O}_{3}$ are formed. The calculated average composition of the inclusions against the temperature obtained by combining the contents of each phase is shown in Figure $6 \mathrm{~b}$.

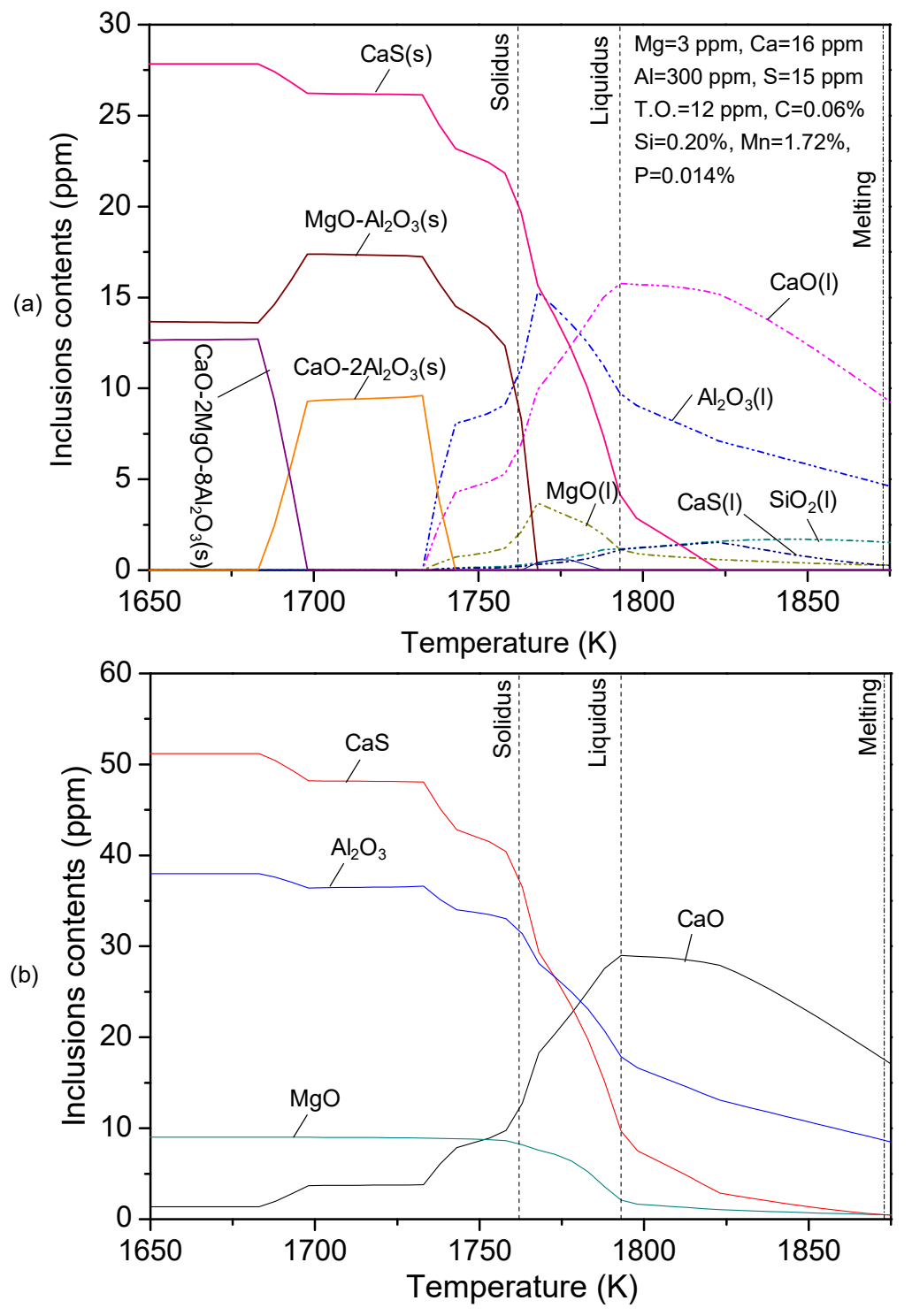

Figure 6. (a) Phase transformation and (b) average composition of inclusions during cooling of X80 pipeline steel. The $\mathrm{CaO}(\mathrm{l}), \mathrm{Al}_{2} \mathrm{O}_{3}(\mathrm{l}), \mathrm{SiO}_{2}(\mathrm{l}), \mathrm{CaS}(\mathrm{l})$ and $\mathrm{MgO}(\mathrm{l})$ are all belong to one slag phase in (a).

At the cooling rate of $10 \mathrm{~K} / \mathrm{s}$, the reaction time is very short, inclusions could not be completely transformed. The inclusions should be mostly formed in the liquid steel. Therefore, the $\mathrm{Al}_{2} \mathrm{O}_{3}-\mathrm{CaO}$ type inclusion was dominantly formed. However, at the slow cooling rate, there is longer time for inclusion to transform. The solid inclusions including $\mathrm{CaS}, \mathrm{MgO}-\mathrm{Al}_{2} \mathrm{O}_{3}, \mathrm{CaO}-2 \mathrm{Al}_{2} \mathrm{O}_{3}$ and $\mathrm{CaO}-2 \mathrm{MgO}-8 \mathrm{Al}_{2} \mathrm{O}_{3}$ can be formed. Therefore, the contents of $\mathrm{CaS}$ and $\mathrm{MgO}$ are increased with the decrease in cooling rate. Consequently, the $\mathrm{CaO}$ content is decreased due to the transformation of $\mathrm{CaO}$ into CaS.

It should be noticed that the thermodynamic prediction is based on the concept of equilibrium, which is useful to help understand the precipitation sequence of the inclusions during cooling, but it cannot be used directly to discuss the amount of inclusions formed. For example, the measured $\mathrm{CaS}$ content at the heating rate of $0.035 \mathrm{~K} / \mathrm{s}$ is much lower than that of the thermodynamic prediction 
in Figure 6b. This should be attributed to the slower precipitation kinetics of CaS, which can be apparently seen in Figure $4 \mathrm{a}$, that only the out-layer of the inclusions was composed by CaS.

From the above discussion it can be concluded that, at the rapid cooling rate, the inclusions are mostly formed at high temperatures, which is retained to room temperature. While, at the slow cooling rate, the inclusions can be gradually transformed and tends to follow the equilibrium compositions at low temperature.

\section{Conclusions}

In the current study, the effects of cooling rate on the formation of inclusions in X80 pipeline steel were investigated. The main results obtained were summarized as follows:

(1) High cooling rate resulted in large number density and fine inclusions, while, the inverse results were obtained at low cooling rate. At a high cooling rate the driving force for nucleation is larger, which increased the nucleation frequency of inclusions, thus resulted in high number density of inclusions. On the contrary, at low cooling rate, the nucleation frequency is lower and the Ostwald-ripening effect is pronounced, which caused the low number density and coarse inclusions.

(2) As the cooling rate decreased from 10 to $0.035 \mathrm{~K} / \mathrm{s}$, the inclusions were changed from $\mathrm{Al}_{2} \mathrm{O}_{3}-\mathrm{CaO}$ to $\mathrm{Al}_{2} \mathrm{O}_{3}-\mathrm{CaO}-\mathrm{MgO}-\mathrm{CaS}$. At a high cooling rate, the reaction time is short and the inclusions cannot be completely formed, which should be mainly formed at high temperatures. At the low cooling rate, the inclusions can be gradually transformed and tends to follow the equilibrium compositions at low temperature.

Author Contributions: X.Z., W.Y. and L.Z., conceived and designed the experiments; X.Z., W.Y. and H.X. performed the experiments and collected the data; X.Z., and W.Y. analyzed the data; X.Z. and H.X. writing-original draft preparation; W.Y. and L.Z. discussed with the results and revised the manuscript. L.Z. supervised and project administration.

Funding: This research was financially supported by the National Key R\&D Program of China (2017YFB0304001, 2016YFB0300102), National Science Foundation China (Grant No. 51874031, No. 51725402 and No. U1860206), the Fundamental Research Funds for the Central Universities (Grant No. FRF-TP-15-067A1), Beijing Key Laboratory of Green Recycling and Extraction of Metals (GREM) and the High Quality Steel Consortium (HQSC) and Green Process Metallurgy and Modeling (GPM2) at the School of Metallurgical and Ecological Engineering at University of Science and Technology Beijing (USTB), China.

Conflicts of Interest: The authors declare no conflict of interest.

\section{References}

1. National Energy Board. Report of Public Inquiry Concerning Stress Corrosion Cracking on Canadian Oil and Gas Pipelines; National Energy Board: Calgary, AB, Canada, 1996.

2. Baker, M., Jr. Stress Corrosion Cracking Studies. Integrity Management Program DTRS56-02-D-70036; TTO 8; bkmuduli, Department of Transportation, Office and Pipeline Safety, 2004. Available online: https: / / www.scribd.com/document/81927365/Scc-Report-Full-Text (accessed on 1 January 2019).

3. Parkins, R.N. A review of stress corrosion cracking of high pressure gas pipelines. In Proceedings of the CORROSION 2000, Orlando, FL, USA, 26-31 March 2000; NACE International: Huston, TX, USA, 2000.

4. Torres-Isla, A.; Salinas-Bravo, V.M.; Albarran, J.L.; Gonzalez-Rodriguez, J.G. Effect of hydrogen on the mechanical properties of X-70 pipeline steel in diluted $\mathrm{NaHCO}_{3}$ solutions at different heat treatments. Int. J. Hydrogen Energy 2005, 30, 1317-1322. [CrossRef]

5. Hara, T.; Asahi, H.; Ogawa, H. Conditions of hydrogen-induced corrosion occurrence of X65 grade line pipe steels in sour environments. Corrosion 2004, 60, 1113-1121. [CrossRef]

6. Kane, R.D.; Cayard, M.S. NACE committee report $8 \times 294$ : Review of published literature on wet $\mathrm{H}_{2} \mathrm{~S}$ cracking. In Proceedings of the CORROSION 1999, San Antonio, TX, USA, 25-30 April 1999; NACE International: San Antonio, TX, USA, 1999.

7. Stephen, S.N. Corrosion of carbon steel by $\mathrm{H}_{2} \mathrm{~S}$ in $\mathrm{CO}_{2}$ containing oilfield environments. In Proceedings of the CORROSION 2006, San Diego, CA, USA, 12-16 March 2006; NACE International: Houston, TX, USA, 2006. 
8. Kittel, J.; Smanio, V.; Fregonese, M.; Garnier, L.; Lefebvre, X. Hydrogen induced cracking (HIC) testing of low alloy steel in sour environment: Impact of time of exposure on the extent of damage. Corros. Sci. 2010, 52, 1386-1392. [CrossRef]

9. Huang, F.; Liu, J.; Deng, Z.J.; Cheng, J.H.; Lu, Z.H.; Li, X.G. Effect of microstructure and inclusions on hydrogen induced cracking susceptibility and hydrogen trapping efficiency of X120 pipeline steel. Mater. Sci. Eng. A 2010, 527, 6997-7001. [CrossRef]

10. Atkinson, H.V.; Shi, G. Characterization of inclusions in clean steels: A review including the statistics of extremes methods. Prog. Mater. Sci. 2003, 48, 457-520. [CrossRef]

11. Wang, X.; Li, X.; Li, Q.; Huang, F.; Li, H.; Yang, J. Control of stringer shaped nonmetallic inclusions of $\mathrm{CaO}-\mathrm{Al}_{2} \mathrm{O}_{3}$ System in API X80 linepipe steel plates. Steel Res. Int. 2014, 85, 155-163. [CrossRef]

12. Liu, D.; Zhai, W.; Liu, Y.; Meng, D. Nonmetallic inclusions removal process of pipeline steel in NISCO. Met. World 2015, 4, 69-71.

13. Ma, Z.; Huang, Z.; Hu, H. Improvement of controlling techniques of inclusions in pipeline steel. Technol. Bao Steel 2014, 5, 14-17.

14. Zhao, D.; Li, H.; Bao, C.; Yang, J. Inclusion Evolution during Modification of Alumina Inclusions by Calcium in Liquid Steel and Deformation during Hot Rolling Process. ISIJ Int. 2015, 55, 2115-2124. [CrossRef]

15. Xu, J.; Huang, F.; Wang, X. Formation Mechanism of CaS- $\mathrm{Al}_{2} \mathrm{O}_{3}$ Inclusions in Low Sulfur Al-Killed Steel after Calcium Treatment. Metall. Mater. Trans. B 2016, 47, 1217-1227. [CrossRef]

16. Miao, K.; Haas, A.; Sharma, M.; Mu, W.; Dogan, N. In-situ observation of calcium aluminate inclusions dissolution into steelmaking slag. Metall. Mater. Trans. B 2018, 49, 1612-1623. [CrossRef]

17. Reis, B.H.; Bielefeldt, W.V.; Vilela, A.C.F. Efficiency of inclusion absorption by slags during secondary refining of steel. ISIJ Int. 2014, 54, 1584-1591. [CrossRef]

18. Tripathi, N.N.; Beskow, K.; Nzotta, M.; Sandberg, A.; Du, S. Impact of slag refractory lining reactions on the formation of inclusions in steel. Ironmak. Steelmak. 2004, 31, 514-518.

19. Yan, P.; Huang, S.; Pandelaers, L.; Dyck, J.V.; Guo, M.; Blanpain, B. Effect of the $\mathrm{CaO}-\mathrm{Al}_{2} \mathrm{O}_{3}$-Based top slag on the cleanliness of stainless steel during secondary metallurgy. Metall. Mater. Trans. B 2013, 44, 1105-1119. [CrossRef]

20. Dong, W.; Ni, H.; Zhang, H.; Lü, Z. Effect of slag composition on the cleanliness of $28 \mathrm{MnCr} 5$ gear steel in the refining processes. Int. J. Miner. Metall. Mater. 2016, 23, 269-275. [CrossRef]

21. Ren, Y.; Zhang, L. Thermodynamic model for prediction of slag-steel-inclusion reactions of 304 stainless steels. ISIJ Int. 2017, 57, 68-75. [CrossRef]

22. Takahashi, I.; Sakae, T.; Yoshida, T. Changes of the nonmetallic inclusion by heating. TetsuHagane 1967, 53, 350-352.

23. Goto, H.; Miyazawa, K.I.; Yanmada, W.; Tanaka, K. Effect of cooling rate on composition of oxides precipitated during solidification of steels. ISIJ Int. 1995, 35, 708-714. [CrossRef]

24. Goto, H.; Miyazawa, K.; Yamaguchi, K.; Ogibayashi, S.; Tanaka, K. Effect of cooling rate on oxide precipitation during solidification of low carbon steels. ISIJ Int. 1994, 34, 414-419. [CrossRef]

25. El-Bealy, M.; Thomas, B.G. Prediction of dendrite arm spacing for low alloy steel casting processes. Metall. Mater. Trans. B 1996, 27, 689-693. [CrossRef]

26. Luo, Y.; Conejo, A.N.; Zhang, L.; Chen, L.; Cheng, L. Effect of superheat, cooling rate, and refractory composition on the formation of nonmetallic inclusions in non-oriented electrical steels. Metall. Mater. Trans. B 2015, 46, 2348-2360. [CrossRef]

27. Yang, C.W.; Lv, N.B.; Zhuo, X.J.; Wang, X.; Wang, W. Study of MnS precipitation on Ti-Al complex de-oxidation inclusions. Iron Steel 2010, 45, 34-36. [CrossRef]

28. Rocabois, P.; Lehmann, J.; Gaye, H.; Wintz, M. Kinetics of precipitation of nonmetallic inclusions during solidification of steel. J. Cryst. Growth 1999, 198, 838-843. [CrossRef]

(C) 2019 by the authors. Licensee MDPI, Basel, Switzerland. This article is an open access article distributed under the terms and conditions of the Creative Commons Attribution (CC BY) license (http://creativecommons.org/licenses/by/4.0/). 